\title{
Campo Grande: a formação da sociedade local e o desenvolvimento de sua identidade cultural
}

Campo Grande: local society organization and cultural identity development

Campo Grande: la formación de la sociedad local y el desarrollo de la identidad cultural

Aparecido Francisco dos Reis

Universidade Católica Dom Bosco

contato: franreis@uol.com.br

\begin{abstract}
Resumo: O artigo a seguir é resultado de pesquisas acerca da formação da mentalidade e da cultura do homem que habita a cidade de Campo Grande e parte do estado de Mato Grosso do Sul. Serão discutidos os modos de pensar, agir e sentir da população local. O estudo foi realizado mediante a observação sistemática do material simbólico como registro de opiniões, dos sentimentos e do pensamento social. Nesse sentido, pensa-se numa sociedade com características agrárias centrada, ainda, numa mentalidade passadista, mas que caminha em direção ao que a sociologia identifica como contínuo folk-urbano, isto é, uma sociedade em transição do rural para o urbano.

Palavras-chaves: cultura; representação do espaço; identidade.
\end{abstract}

\begin{abstract}
The following article is the result on the formation on of the mentality and culture of the man who inhabits the city of Campo Grande and part of the state of South Mato Grosso. In the article the ways of thinking, acting and feeling of the local population are discussed. The study is based on systematic observation of symbolic material such as: registering of opinions, feelings and social though. In this way, one can think of a society with agrarian characteristics still center on thoughts of the past but going in the direction of what sociology identifies as continuous folk-urban. That is, a society in transition from the rural to the urban.
\end{abstract}

Key words: culture; space representation; identity.

Resumen: El artículo que sigue es el resultado de pesquisas acerca de la formación de la mentalidad y de la cultura del hombre que habita la ciudad de Campo Grande y parte del Estado de Mato Grosso do Sul. En este estarán discutidas, los modos de pensar, actuar y sentir de la populación local. El estudio fue realizado mediante la observación sistemática del material simbólico como: registro de opiniones, de los sentimientos y del pensamiento social. En ese sentido, se piensa en una sociedad con características agrarias centrada aún, en una mentalidad antigua pero en dirección al que la sociología identifica como continuo folk-urbano; o sea una sociedad en transición del rural para el urbano.

Palabras claves: Cultura; representación del espacio; identidad.

A sociedade campo-grandense teve suas origens totalmente ligadas ao mundo rural tanto nas atividades econômicas quanto culturais. Pode-se falar em uma sociedade com uma cultura ligada às formas de sociabilidade e de subsistência que se apoiava em soluções econômicas mínimas. A economia e o trabalho estavam condicionados pela grande extensão de terras nas quais se cultivavam a agricultura e a criação de gado, sendo este último o elemento econômico preponderante na constituição da sociedade local. Assim sendo, enquanto cidade, Campo Grande e o próprio sul de Mato Grosso nasceram e se consolidaram a partir da criação de gado feita em grandes extensões de terras:

Esse sistema se realiza em grandes áreas ou propriedades, ele depende muito mais dos recursos naturais - pastagens, barreiros salinos - do que recursos zootécnicos. A adoção desse processo de criação propicia a formação de grandes latifúndios, porque a baixa rentabilidade da exploração do gado é compensada pela expansão quantitativa de dois fatores básicos, a terra e o gado (Weingartner, 1995, p. 18).

Segundo a autora acima citada, o gado é que fez a base econômica. Espalhando-se pelas campinas e pelo cerrado aberto das terras da região, possibilitando a formação das fazendas e o aparecimento dos nú- cleos urbanos, ensejando a formação da agricultura. Criar gado tornou-se a profissão normal do tipo médio do habitante da cidade e de suas adjacências.

Desde o início do século XX, Campo Grande, assim como todo o sul de Mato Grosso, é uma região eminentemente pastoril. Toda circulação de dinheiro e de outras atividades estavam diretamente associadas ao boi, como pode-se verificar na descrição de Paulo Coellho Machado (1990).

No declínio, a cidade esvazia-se para recredescer o movimento, com maior embalo, na alta do boi. Então a cidade assumia novamente o ar alegre e brejeiro, porque nós sempre dependemos e vamos depender por muito tempo dos negócios pecuários. Novos bares e estalagens foram abertos, cabarés nasciam a todo instante, ao lado do comércio de gêneros alimentícios, armazéns, bazares e outros que foram se aperfeiçoando. Mulheres de todas as partes procuram a cidade, onde corria dinheiro a rodo. Logo começaram a chegar também as jovens paraguaias, internacionalizando e valorizando a zona campograndese. Frescas, bonitas, amoráveis, desinibidas, falando e ensinando o guarani... Trouxeram a polca e a dolente guarânia, logo incorporadas ao nosso folclore e cantadas ao vilão dia e noite (Machado, 1990, p. 80).

Campo Grande transformou-se no lugar preferido dos boiadeiros, dos viajantes, dos negociantes de toda espécie, pela colo- 
cação próxima dos centros produtores, fertilidade das terras e pelo acúmulo de capital por parte de vários fazendeiros.

\section{Agricultura e trabalho}

Outros pontos importantes no entendimento do habitante local são suas concepções de produção e de trabalho.

Na produção agrícola havia a predominância de uma economia de subsistência, associada a grande quantidade e a fertilidade das terras. Plantava-se para viver, a colheita era enorme se comparada com o plantio. Em caso do enfraquecimento do solo, associado à precariedade da técnica, era possível recorrer a novas terras, onde se recriavam as condições anteriores, não apenas de produtividade, como de isolamento, perpetuando a auto-suficiência e tornando desnecessária a introdução de hábitos mais rigorosos de trabalho, condizentes com o modo de produção capitalista.

Essa prática tornou-se comum no interior do Brasil, como se pode observar ao fazer a leitura de textos referentes à cultura e ao tipo rural brasileiro.

Em Os Parceiros do Rio Bonito (1962), Antônio Cândido discute as transformações nos meios de vida e padrões de sociabilidade do caipira paulista tradicional, relacionandoas às mudanças socioculturais que acompanharam os processos de urbanização e industrialização no estado de São Paulo. Abandonando a intenção original de investigar o impacto do processo de mudança nas manifestações folclóricas, mais precisamente no cururu, dança típica da região pesquisada, o sociólogo acabou desenhando um retrato do homem, conhecido como o rústico.

O conceito de cultura rústica baliza a análise do autor, que acentua a necessidade de distingui-lo de folk-culture, pois, se em ambos trata-se do tema do isolamento relativo e da incorporação e reinterpretação de traços culturais, que vão se alterando ao longo do contínuo folk-urbano, cultura rústica indica um padrão específico de contato interétnico e cultural. Entende, dessa forma, que:

No caso brasileiro, rústico se traduz praticamente por caboclo no uso dos estudiosos, sendo provavelmente Emílio Willems o primeiro a utilizar de modo coerente a expressão cultura cabocla; $\mathrm{e}$ com efeito aquele termo exprime as modalida- des étnicas e culturais do referido contacto do português com o novo meio (Candido, p. 22).

A análise de Antônio Cândido aproxima a cultura cabocla do caipira à existência nômade ou semi-nômade, associada ao processo de conquista dos sertões. $\mathrm{O}$ fato teria suas raízes históricas no fenômeno das entradas e bandeiras, pois como nos adverte o autor:

A expansão geográfica dos paulistas, nos séculos XVI, XVII e XVIII, resultou não apenas na incorporação do território às terras da Coroa portuguesa na América, mas na definição de certos tipos de cultura e vida social, condicionados em grande parte por aquele grande fenômeno de mobilidade. Não cabe analisar aqui o seu sentido histórico, nem traçar o seu panorama geral. Basta assinalar que em certas porções do grande território devassado pelas bandeiras e entradas - já denominado significativamente Paulistânia - as características iniciais do vicentino se desdobraram numa variedade subcultural do tronco português que se pode chamar de cultura caipira (p. 35).

Um lençol de cultura caipira teria se estendido, assim, em fins do século XVIII, pelas capitanias de São Paulo, Minas Gerais, Goiás e também aqui em Mato Grosso do Sul, em que se revelam formas de sociabilidade e sobrevivência caracterizadas por soluções mínimas. Segundo esse argumento histórico, o homem rústico do interior, por conseguinte aqui do Centro-Oeste, teria herdado do bandeirante a esquivança, o laconismo, a rusticidade e, como corolário da grande mobilidade e dos padrões mínimos de vida, o espírito de aventura: "na habitação, na dieta, no caráter do caipira, gravou-se para sempre o provisório da aventura" (p. 37). A principal característica dessa cultura consistia na rusticidade, resultado do encontro de padrões culturais europeus, no caso específico de espanhóis e portugueses com os de etnias indígenas, modelando esses últimos, em grande parte, o modo de ser da população local.

Segundo o autor, a dieta alimentar do elemento rústico resultaria dessa vida nômade e apresentava sensível semelhança com a dos bandeirantes. O leite, o trigo e a carne de vaca seriam itens muito raros e a caça, atividade caipira por excelência. Nela se "desenvolvia a extraordinária capacidade de ajustamento ao meio, herdada do índio" (p. 55). Também na habitação a provisoriedade estava gravada. A casa, um abrigo de palha 
sobre paredes de pau-a-pique, recebia o nome de "rancho", indicando o caráter de pouso que tinha para o morador (p. 37).

O sociólogo não se detém muito a explicar como uma característica cuja origem histórica remontava ao bandeirismo e a um certo padrão de povoamento se cristalizara, mais preocupado que estava com o processo de mudança nas áreas tradicionais de São Paulo, como efeito da industrialização e da urbanização. Tratava-se também de pensar como traços culturais vistos como garantidores de "equilíbrio ecológico", portanto funcionais ao modo de vida caipira, se comportariam nas novas condições de organização social. Por conseguinte, não restam dúvidas ao autor que a cultura caipira ou cabocla, caracterizada por relativa independência em relação aos núcleos urbanos, disponibilidade de terras, trabalho doméstico, auxílio vicinal e acentuado tempo disponível para as atividades de lazer, representava um padrão adaptativo às condições do meio:

Tendo conseguido elaborar formas de equilíbrio ecológico e social, o caipira se apegou a elas como expressão da sua própria razão de ser, enquanto tipo de cultura e sociabilidade. Daí o atraso que feriu a atenção de Saint-Hilaire e criou tantos estereótipos, fixados sinteticamente de maneira injusta, brilhante e caricatural, já neste século, no Jeca Tatu de Monteiro Lobato (p. 82).

O estereótipo da indolência explicavase pela organização da cultura, tanto em termos biológicos, e daí a importância dos estudos da alimentação, como sociais, em torno de padrões mínimos, daí resultando uma margem de lazer maior. Esses padrões trariam dificuldades para a adaptação posterior a novos ritmos de trabalho e a eles também se somavam características da saúde e da nutrição, apontadas muitas vezes como causas únicas. A preguiça é percebida por Cândido, como um dado não contingente, como um traço cultural do caipira. E explicada pela estabilização de sua vida "em termos biológicos e sociais em torno de padrões mínimos" (p. 86). Assiste-se, dessa forma, a uma nova inversão da célebre frase de Monteiro Lobato: o Jeca não "estava assim", ele realmente "era assim", dados os padrões culturais que organizavam a sua vida social, uma vida "mínima".

Apesar de Antônio Cândido não se referir à idéia de espírito ou mentalidade capitalista como se vê na análise de Max Weber acerca do tipo social básico forma- dor do capitalismo nórdico-europeu, é possível pensar nesse tema como pano de fundo de seu trabalho. Tal afirmação é compreendida a partir da leitura de A ética protestante e o espírito do capitalismo (1980).

Em Weber, o capitalismo como forma econômica não poderia ter se desenvolvido sem uma mudança de visão de mundo básica. Assim, Weber foi conduzido à idéia de que a explicação para o fato deveria ser encontrada na estreita vinculação do capitalismo com a ascese puritana. $O$ fato, de na época, os líderes do mundo dos negócios, os proprietários do capital e os níveis mais altos de mãode-obra qualificada, e, sobretudo, trabalhadores disciplinados e com obrigação moral para o trabalho, serem, na sua maioria, protestantes, demonstraria, segundo Weber, uma tendência, nestes, para o racionalismo econômico. A razão para este fato, Weber busca no caráter intrínseco e permanente de suas crenças religiosas e não apenas em suas temporárias situações políticas e históricas.

É exatamente no calvinismo que Weber passa a centrar sua análise no sentido de perceber na visão de mundo apontada aqui, os elementos básicos guiadores do comportamento puritano: isolamento espiritual do indivíduo em relação a Deus; racionalização do mundo e a eliminação do pensamento mágico, como meio de salvação. Deste modo, com o intuito de relacionar as idéias fundamentais do ascetismo puritano com as tendências econômicas, Weber aponta alguns elementos coincidentes: o trabalho como a própria finalidade da vida; o sucesso profissional e a riqueza do indivíduo como provas do cumprimento de sua vocação e da escolha divina, diferentemente do caipira estudado por Antônio Cândido.

A ascese puritana teria, então, libertado o fiel para a ânsia do lucro como um desejo de Deus. Com isso, Weber quer dizer que se precisa considerar a especificidade das relações entre a economia e as representações de mundo dos sujeitos de uma determinada sociedade.

Weber salienta, de um lado, para a importância de se pesquisar as idéias como parte da realidade social e, de outro, para a necessidade de se compreender a que instâncias do social, determinado fato deve sua maior dependência. 
Parece que o caipira ou o Jeca pode ser compreendido como o inverso do calvinista, formado em outra visão de mundo em relação ao trabalho. Cândido afirma que o Jeca "não é vadio, simplesmente não é ambicioso nem previdente" (p. 87). Tal condição aparece simbolicamente reforçada pelas origens históricas, reais ou míticas, que explicariam o sentido de independência do caipira e que o teriam colocado à margem de relações escravistas ou servis. Por isso, surgiam expressões como a registrada por Antônio Cândido: "sino é para italiano", no caso do estado de São Paulo, que procurava "dar expressão étnica a duas tradições culturais diversas: a do imigrante europeu formado secularmente nos padrões de dependência senhorial; a do caipira, herdeiro da aventura de desbravamento e posse franca dos sertões" (p. 189).

As relações de trabalho e a propalada preguiça não poderiam ser dissociadas da estrutura fundiária, pois expulso das posses, nunca legalizadas, o "Jeca" persistia como agregado, ou "buscava sertão novo, onde tudo recomeçaria" (p. 82). Apenas a partir das décadas de 1940 e 1950 sua incorporação à vida das cidades se teria tornado apreciável. Em seu estudo, Antônio Cândido, ao procurar responder à pergunta de como se comportou a cultura caipira ante os fatores de desequilíbrio representados pelo latifúndio produtivo comercializado, o desenvolvimento urbano e o imigrante (p. 91), chega à conclusão de que "há resistência variável da cultura caipira segundo as formas de ocupação da terra, regime de trabalho e situação legal. Onde há concentração de sitiantes e ausência de latifúndio, vemos permanecerem com mais integridade as relações vicinais e o sentimento local" (p. 91).

O desamor ao trabalho do habitante do sertão estava ligado à desnecessidade de trabalhar, condicionada pela falta de estímulo prementes à técnica sumária e a espoliação eventual da terra. Foi peculiar ao habitante local a dedicação a outros afazeres como: a caça, a pesca e a indústria doméstica; e ainda atividades lúdicas como festas e celebrações, que aprofundavam as relações sociais entre vizinhos, parentes e compadres, mantendo assim, a homogeneidade e coesão social, consideradas mais importantes que as atividades econômicas.
O trabalho encontrava-se ainda racionalizado pela observância dos dias de guarda, considerados pelos mais velhos como "dias desastrosos", nos quais se acreditava que o trabalho podia causar prejuízo grave, devido ao desrespeito às normas religiosas. Se para a maioria a semana conta com seis dias úteis, para o sertanejo conta apenas quatro. No sábado ele não vai à roça, fica em casa preparando os seus aviamentos de caça e pesca, ou em preparativos para ir ao domingo à vila; na segunda, ele descansa da fadiga do domingo. Entretanto, segundo Antônio Cândido isso não quer dizer que o homem rural fosse um vadio. Simplesmente não era ambicioso e nem previdente. Podendo apenas ser interpretado como um tipo que não tinha extremas necessidades, portanto, tendo uma concepção de trabalho própria em um universo relativamente fechado e homogêneo de uma cultura rústica em territórios vastos.

Apesar da idéia corrente do isolamento das culturas sertanejas, Antônio Cândido oferece indícios de que tal condição seria reforçada, no caso dos parceiros do Rio Bonito, pelo avanço da civilização urbana. Tradicionalmente, a estrutura fundamental da sociabilidade caipira era o bairro - "agrupamento de algumas ou muitas famílias, mais ou menos vinculadas pelo sentimento de localidade, pela vivência, pelas práticas de auxílio mútuo e pelas atividades lúdico-religiosas" (p. 62). Poucas frases seriam tão expressivas dessa realidade do que "o bairro é uma naçãozinha", registrada pelo sociólogo no curso de sua pesquisa, indicando a consciência de pertencimento e identidade dos moradores.

No bairro caipira é que se deveria buscar, de acordo com o autor, o sentido de autonomia ao poder centralizador do grande domínio rural e à independência do fazendeiro. O sentido sociológico da autarquia econômico-social não deveria ser buscado no latifúndio, "largamente aberto às influências externas, graças à sua própria situação de estrutura líder, e sim no bairro caipira, nas unidades fundamentais de povoamento, da cultura e da sociabilidade, inteiramente voltados sobre si mesmos" (p. 81).

Esse padrão de sociabilidade sofre profunda alteração no processo de transição da 
economia de subsistência para a economia capitalista, quando cada vez mais a vida social do caipira se fecharia no bloco familiar, implicando a perda das relações vicinais e dos laços organizados em torno do bairro. Antônio Cândido descreve-a como crise econômica, crise no padrão de vida e também crise sociocultural; percebendo-a como anomia, uma vez que:

A sua vida anterior comportava ritmo diverso, que não era estritamente determinado [...] pelas necessidades econômicas mais elementares, de que depende a própria sobrevivência. A par do trabalho agrícola, ocupava-se também com a vida comemorativa, a vida mágico-religiosa, a caça, a pesca, a coleta, as práticas de solidariedade vicinal [...] este conjunto de circunstâncias favorecia tanto o melhor ajustamento ecológico possível a uma situação a limentar medíocre, quanto à integração social mais plena (p. 169).

Em face da civilização urbana, a situação de equilíbrio ecológico da vida tradicional do caipira teria sido desestruturada, o que se faria sentir em diversos aspectos, sendo a alimentação um dos mais relevantes. A monotonia da dieta composta basicamente por feijão, arroz, farinha e pouquíssima carne (mesmo a caça era rara) é acentuada pelo autor que descreve, com detalhes, o cardápio semanal de um caipira.

\section{A sociedade de transição}

Pode-se identificar pelo menos duas fases no processo de transição nesta sociedade com cultura eminentemente agrária com destino a uma sociedade urbana. A primeira fase ocorre concomitante à migração do homem do campo, a partir da década de 50. Evidentemente, Mato Grosso do Sul tem suas especificidades, pois em outras cidades, a urbanização se deu, principalmente em virtude da industrialização, sobretudo São Paulo. Aqui essa transferência ocorre mais posteriormente, no momento da divisão do estado de Mato Grosso. Nesse sentido, cidades como Campo Grande e Dourados, crescem e passam receber um fluxo maior de pessoas. A descrição da evolução da população do estado pode ser verificada na tabela abaixo.

Tabela 1: Taxa geométrica de crescimento da população residente - 1970/2000.

\begin{tabular}{|l|c|c|c|c|}
\hline \multirow{2}{*}{ SITUAÇÃO DE DOMICÍLIO } & \multicolumn{4}{|c|}{ POPULAÇAO } \\
\cline { 2 - 5 } & $\mathbf{1 9 7 0}$ & $\mathbf{1 9 8 0}$ & $\mathbf{1 9 9 1}$ & $\mathbf{2 0 0 0}$ \\
\hline RURAL & 546.087 & 450.444 & 365.926 & 330.895 \\
\hline URBANA & 452.117 & 919.123 & 1.414 .447 & 1.747 .106 \\
\hline TOTAL & $\mathbf{9 9 8 . 2 0 4}$ & $\mathbf{1 . 3 6 9 . 5 6 7}$ & $\mathbf{1 . 7 8 0 . 3 7 3}$ & $\mathbf{2 . 0 7 8 . 0 0 1}$ \\
\hline
\end{tabular}

Fonte: IBGE.

Foram apresentados aqui os dados das últimas quatro décadas, isto é, desde os anos 70, período da divisão e criação do estado de Mato Grosso do Sul. A partir destes, pode-se observar que a transferência da população da zona rural para as cidades do estado, foi extremamente rápida. No geral, o crescimento demográfico foi mais acelerado na década de 70, período que corresponde à entrada de migrantes gaúchos que vieram trabalhar no cultivo de soja. Na década de 80 a taxa verificada foi de 2,4, mas segundo estimativas do IBGE (Instituto Brasileiro de Geografia e Estatística), no período correspondente à década de 90 , o crescimento da população girou em torno a $1,86 \%$ ao ano.

Considerando que o Estado de Mato Grosso do Sul encontra-se ainda em proces- so de ocupação, possui uma densidade populacional baixa de 5,25 habitantes por quilômetro quadrado, apresentando grandes vazios demográficos, como a microrregião Baixo Pantanal com uma densidade de apenas $1,37 \mathrm{habit} / \mathrm{km}^{2}$. Por outro lado, pode-se perceber que aproximadamente $50 \%$ da população habitam as regiões de Dourados e Campo Grande, totalizando 1.131.474 moradores segundo o Censo Demográfico do IBGE de 2000.

Como pode-se perceber nas análise dos dados do IBGE, a grande mudança da população para a zona urbana ocorreu na década de 70. Nesse período, introduziram-se no seio da sociedade agrícola, novas técnicas de produção, organizadas segundo o padrão capitalista. Ou seja, a mecanização 
dos processos agrícolas, como na produção de soja, trigo, milho em várias regiões do estado, principalmente na região de Dourados, torna o Estado o $8^{\circ}$ produtor de grãos do país. Também, no período, a atividade pecuária sofre mudanças no sentido do ajustamento aos modernos processos de criação de gado de corte e de leite, contado em 2000, segundo a SEPLANCT (Secretaria de Estado de Planejamento, Ciência e Tecnologia), com um rebanho de aproximadamente de 25 milhões de bovinos.

O fato do estado ocupar um lugar de destaque nas atividades agro-pecuárias não se traduz imediatamente numa situação cômoda para a população local. Também a migração da zona rural para as cidades trou$x e$, do ponto de vista dos sujeitos sociais mudanças econômicas e novas formas de entendimento do mundo. Numa entrevista realizada com uma senhora, moradora de Campo Grande, entre outras informações, pode-se observar uma certa saudade da fazenda, uma vez que a mesma, vivendo na cidade numa situação bastante adversa, revela as suas representações e o seu saudosismo de um tempo passado, que ao que parece, era bem melhor que presente.

O mundo meu filho é um grande teatro. Esse grande teatro é formado por três tipos menores, diferentes. O da roça, por oferecer melhores condições à vida, ar puro, e até levemente perfumado, fartura, abundância de água limpa e corrente, tranqüilidade, ocupa o primeiro lugar na classificação. O segundo colocado é o tipo formado pelas cidades interioranas, pequenas, nas quais as pessoas vivem em harmonia, são amigas, cooperam para o bem-estar da comunidade. A terceira colocação coube ao tipo formado pela grande cidade, o tal mundo civilizado, onde há poluição do ar e sonora, maior número de sofredores, de doentes, de acidentes e ladrões e de crimes de todo tipo (Rosa, 68 anos).

Esta senhora foi criada numa fazenda em uma cidade do interior do Estado de Mato Grosso do Sul. Morando atualmente em Campo Grande e, em grande medida dependendo da ajuda dos filhos para sobreviver e sem aposentadoria, a mesma, embora de forma serena entende que o mundo de hoje perdeu os referenciais e os valores que tornam os seres humanos mais próximos uns dos outros. Sem dúvida essas formas de representação são comuns, sobretudo nos mais velhos e mais pobres que tiveram contato com a vida tradicional e podem compará-la com o presente. Verifica-se isso nas palavras de João Santana (58 anos), morador de Campo Grande. Sua família veio da Bahia, quando ele ainda era criança, para trabalhar na agricultura na região de Dourados, hoje ele é aposentado como ex-funcionário da Enersul (Empresa de Energia Elétrica de Mato Grosso do Sul) e tem uma pequena mercearia num bairro de Campo Grande. Segundo ele, o que recebe como aposentado não é suficiente para o sustento da família, com 5 filhos, ainda solteiros e todos morando com ele. São ainda muito jovens, uma vez que se casou já com uma idade meio avançada. Embora cansado, se vê na obrigação de trabalhar mais um pouco ainda para poder sobreviver junto com sua família.

Para ele, a vida numa cidade como Campo Grande não tem sido das mais tranquilas. Alega que tem muitas despesas e poucas compensações, já que o modelo econômico não propicia uma melhora de situação. Ele percebe que em relação aos seus pais ele está melhor, tem mais conforto, mas isso representa um ônus muito grande, já que tem de se comprar de tudo hoje em dia. O passado dele na zona rural era marcado por dias bem melhores que os atuais. Assim sendo, pode-se notar representações muito presentes na sua fala quando compara passado e presente:

1 - A abundância: reino da fartura. Grandes colheitas, onde se deixava "milho no pé para os porcos comerem";

2 - A solidariedade: todos se ajudavam mutuamente e ninguém passava aperto. O mutirão foi largamente praticado em toda zona rural do estado, representando para o roceiro: benefício, auxílio, obrigação moral de retribuir a ajuda e também uma dimensão lúdica: a festa;

3 - A sabedoria: havia gente que contava causos. Causos de santos, bichos, milagres. Todos com a função de instruir os mais novos. Uma espécie de tradição oral. Lembra que havia mais respeito e temor: os filhos obedeciam aos pais, os jovens aos mais velhos, os afilhados aos padrinhos e toda lei divina.

Essa valorização do passado, embora seja contada e apareça como real, é apenas uma imagem ideal. No passado havia doenças, mortes e recursos escassos. Mas é o tem- 
po onde aparecem os valores fundamentais desse tipo de cultura, tais como lealdade, amizade, compadrio, entre outros. $\mathrm{O}$ fato de estarem morando hoje na cidade, não significa que se sintam completamente integrados. A impressão é que alguns indivíduos não cabem no universo da cidade, revelando a anomia apontada acima por Antônio Cândido no que se refere ao desmantelamento da cultura dos caipiras paulistas.

Integrando-se ou não ao universo urbano, esses sujeitos sociais encontram-se numa situação de aprender os novos estoques simbólicos disponíveis. O problema aparece porque não existe um equilíbrio na aquisição destes novos elementos, logo a mentalidade social oscila entre o mundo da cidade com seus valores, crenças, sentimentos e práticas sociais modernas e o mundo rural, mítico, onde o tempo parece não mudar, e se muda é para permanecer numa eternidade obedecendo os ciclo da natureza.

Tais situações revelam um profundo romantismo rural, passadista, a despeito do discurso em nome do futuro. A nostalgia pode ser vista como uma forma clássica de romantismo por aqueles que se recusam à alienação, aos conflitos de um tempo, e buscam num passado pré-urbano a utopia do tempo novo. No caso de Mato Grosso do Sul, a raiz desse romantismo está na idéia de que o atraso é uma condição determinante e ponto fundamental a ser superado, pois todos os males econômicos, sociais e políticos são dele advindos. Para tanto, na visão de parte dos habitantes da cidade e, sobretudo do Governo do Estado, há a necessidade de introduzir uma nova mentalidade através de capitalismo na forma de desenvolvimento industrial, da criação de uma burguesia urbana em detrimento dos grandes latifundiários e por fim, do rompimento definitivo com as práticas políticas tradicionais como o clientelismo e o paternalismo:

Acho que o governo do Estado pode não ser lá muito competente para administrar o Estado e tenha provocado ate hoje muita decepção no povo. Todo mundo aqui em Campo Grande esperava uma saída melhor, um maior investimento na área industrial. As pessoas queriam que a indústria viesse para Campo Grande e isso iria provocar emprego e ganho. O governo está trazendo indústria só para Três Lagoas, Aparecida do Taboado, ali perto de São Paulo.
Não acho o governo bom, mas pelo menos é honesto e não rouba como os anteriores. As pessoas reclamam, mas não se lembram que esse Estado passou vinte anos sendo mal administrado e roubado pelos políticos tradicionais que se alterarm no poder. O Estado está quebrado e nem tem como fazer novos investimentos (Leila, 46 anos - dona de comércio).

O depoimento de Leila demonstra a frustração que o governo administrado pelo PT (Partido dos Trabalhadores), tem, de certo modo, provocado. Como é sabido, desde a divisão do Estado no fim de da década de setenta, ele tem sido governado apenas por dois grupos políticos ligados à estrutura agrária, aos grandes latifundiários. Apenas em 1998, a hegemonia latifundiária foi supostamente rompida com a eleição de José Orcírio dos Santos, conhecido como Zeca do PT, para o governo estadual. As expectativas acerca do governo do PT giram, sobretudo, na idéia de criação de uma sociedade com estilo mais capitalista com incentivos a industria, o que teria como decorrência a menor dependência das atividades agro-pecuárias. Evidentemente, nenhuma mudança de comportamento nas ações do governo podem ser isoladas do restante da ação da população como um todo. A mentalidade está associada a formas tradicionais e fossilizadas, logo, a mudança parece ser algo ainda muito distante. Na continuação de sua fala, Leila diz:

O Zeca não traz indústria para cá porque aqui em Campo Grande não tem mão-de-obra qualificada. As indústrias que se instalaram em Três Lagoas, trouxeram gente de São Paulo para trabalhar. Pegou pouca gente da cidade. Claro, prefere gente com capacidade para trabalhar e aqui não tem. Eu sou dona de comércio e sei que isso é difícil. Não se encontra gente competente para nada aqui.

Esses diagnósticos se recusa a ver que as mazelas e os problemas do Estado estão colocados na sua própria formação histórica e no contexto de uma sociedade que pode ser identificada como em direção à urbanização, e por isso, provocando saudade ou perspectiva de novo tempo. Não pode haver esperança de que um governo, seja ele qual for, possa ser o agente exclusivo de mudança.

Assim sendo, tem-se de pensar no urbano ou no rural, no mínimo em duas perspectivas: a das estatísticas e a da cultura ou estilo, sendo aqui entendida como uma forma de pensar, agir e sentir dos indivíduos 
ou ainda, como um modo peculiar de "fazer as coisas" (DaMatta, 1998, p. 17).

A partir da perspectiva dos dados demográficos, Campo Grande pode ser pensada como uma cidade. Isso pode ser confirmado tendo como referência os critérios adotados no Brasil para definir o que é uma região urbana. Na verdade, a socióloga Maria Narazeth Wanderlei Baudel (1997) aponta que o critério mais freqüentemente utilizado para distinguir uma sociedade rural da urbana é o tamanho da população. Segundo Wanderlei Baudel, cada país estabelece o limite além do qual um aglomerado pode ser visto como urbano. Na França é acima de 2.000 habitantes; nos Estados Unidos, o limite varia entre 10.000 e 50.000 habitantes e na Alemanha é considerado como rural toda região que sofrer ausência de uma cidade com mais de 100.000 habitantes.

No Brasil, segundo a referida autora, existem dois critérios estabelecidos. Pela legislação, atribui-se a toda sede de município a condição de urbana e, do mesmo modo, são igualmente urbanos conglomerados populacionais, às vezes, de dimensões muito reduzidas, como é o caso da maioria das sedes distritais.

Partindo dessa concepção, compreende-se que Campo Grande se enquadra como uma sociedade urbana, assim como as demais cidades brasileiras. A legislação não considera como relevante se parte da população mora no espaço urbano e exerce profissões ligadas ao espaço da zona rural.

Por outro lado, outros autores enfatizam que rural e urbano são conceitos que perpassam a noção de território e de tamanho de população, sendo compreendidos, portanto, a partir do tipo de sociedade ou mentalidade que se pode identificar.

Segundo Ruben George Oliven (1996), as teorias sociais que lidam com esses conceitos apontam para um contraste entre os dois modelos de sociedade. Nesse contexto, existe a teoria do antropólogo norte americano Robert Redfield (1941). Seu modelo é construído a partir de estudos com camponeses migrantes para a Cidade do México. Neste, o autor procura confrontar características de uma sociedade não urbana com a de uma urbana. Assim, ele apresenta uma sociedade não urbana como: "Pequena, iso- lada, analfabeta e homogênea, com forte sentimento de solidariedade grupal" (Oliven, 1996, p. 13).

Neste tipo de sociedade descrita por Redfield, os modos de vida e o comportamento são tradicionais e espontâneos. O parentesco, as relações pessoais, o grupo familiar e suas instituições aparecem como fundamentos em detrimento da legislação que igualaria todos os indivíduos:

A vila camponesa quando comparada com a vila tribal, a cidade pequena quando comparada com a vila camponesa, ou a cidade grande quando comparada com a cidade pequena é menos isolada; é mais heterogênea; é caracterizada por uma divisão do trabalho mais complexa; tem uma economia monetária mais completamente desenvolvida; tem especialistas profissionais que são mais seculares e menos sagrados; tem instituições de parentesco e compadrio que são bem menos eficazes no controle social (Oliven,1996, p. 15).

O autor aponta que a sociedade urbana é menos religiosa, mais racional e apresenta uma menor tendência de atribuir a doenças ou outros males uma relação imediata com a quebra de conduta moral e dos costumes tradicionais. Também a sociedade urbana permite uma ação maior de liberdade para o indivíduo. A partir da definição de Redfield, a sociedade urbana é uma coletividade dividida em grupos e classes sociais e na qual há indivíduos isolados uns dos outros. Os membros de uma sociedade com esse grau de complexidade não se conhecem pessoalmente e, assim, se relacionam mediante certas instituições sociais como Estado, escolas, igrejas, meios de comunicação, comércio e grandes rituais coletivos.

Por outro lado, o modelo de Redfield deve ainda ser compreendido como um momento de transição entre os dois modelos organização social. Assim, haveria sempre um direcionamento da sociedade rural para sociedade urbana, dependendo, é claro, do grau de heterogeneidade das relações sociais e da densidade populacional. As consequiências do deslocamento rumo ao urbano seriam a desorganização da cultura, a secularização e o individualismo. Desse modo, a homogeneidade de uma sociedade rural, com uma estrutura monolítica, seria substituída na sociedade urbana, por uma diversidade de papéis, ações e significados. A cultura rural se fragmentaria, tendo então, como desfecho final, a desorganização e o conflito. 


\section{Referências bibliográficas}

CÂNDIDO, Antônio. Os parceiros do Rio Bonito. São Paulo: Duas Cidades, 1962.

Formação da Literatura Brasileira. 2. ed. Belo Horizonte: Itatiaia, 1981.

DAMATTA, Roberto. O que faz brasil, Brasil? 9. ed. Rio de Janeiro: Rocco, 1998.

IBGE (Instituto Brasileiro de Geografia e Estatística) Censo 2000

MACHADO, Paulo Coelho. A rua velha. Campo Grande: Tribunal de Justiça de Mato Grosso do Sul, 1999.

MATO GROSSO DO SUL. Cenários para Mato Grosso do Sul 1999-2000. Secretaria Estadual de Planejamento, Ciência e Tecnologia, 2000.
OLIVEN, Ruben George. Urbanização e mudança social no Brasil. Petrópolis: Vozes, 1982.

Antropologia de grupos urbanos. 4. ed. Petrópolis: Vozes, 1996.

REDFIELD, Robert. The folk culture of Yucatan. Chicago: University of Chicago Press, 1941.

VANDERLEI, Maria Nazareh Baudel. O que há de moderno no Brasil rural. Caxambu: ANPOCS, 1997.

WEBER, Max. A ética protestante e o espírito do capitalismo. São Paulo: Abril Cultural, 1980. (Os pensadores).

WEINGARTINER, Alisolete do Santos. O movimento divisionista em Mato Grosso do Sul. Porto Alegre: Edições Est., 1995. 